\title{
Pulmonary sarcoidosis in children: a follow-up study
}

\author{
A. Baculard*, N. Blanc*, M. Boulé*, B. Fauroux*, K. Chadelat*, L. Boccon-Gibod", \\ G. Tournier*, A. Clement*
}

Pulmonary sarcoidosis in children: a follow-up study. A. Baculard, N. Blanc, M. Boulé B. Fauroux, K. Chadelat, L. Boccon-Gibod, G. Tournier, A. Clement. C) ERS Journals Ltd 2001.

ABSTRACT: Progression of pulmonary sarcoidosis in children remains poorly documented. The aim of this work was to gather follow-up information on pulmonary outcomes in children with sarcoidosis and to obtain data of relevance to a discussion of the optimal length and regimen of glucocorticoid therapy.

In the present study, the authors experience of pulmonary sarcoidosis in 21 children referred to the paediatric pulmonary department over a 10-yr period is reported with a documented follow-up of at least 4 yr. Evaluation of the disease during the follow-up included analysis of clinical manifestations, chest radiographs, pulmonary function tests with measurements of the vital capacity $(\mathrm{VC})$, dynamic lung compliance $(C \mathrm{~L}, \mathrm{dyn})$, lung transfer for $\mathrm{CO}(T \mathrm{~L}, \mathrm{CO})$, and arterial blood gases, as well as bronchoalveolar lavage (BAL) with determination of total and differential cell counts.

After initial evaluation the decision was a careful observation of four children without therapy. Corticosteroid treatment was initiated in 17 children. Analysis of results indicated that after 6-12 months of treatment most clinical manifestations of the disease and chest radiograph abnormalities disappeared, and beneficial effects on $\mathrm{VC}$ and $T_{\mathrm{L}, C O}$ were apparent. After 18 months of steroids no benefit on pulmonary function tests could be noticed, with mainly persistence of alterations of $C L$,dyn. Results of BAL studies documented the presence of an alveolitis with increased lymphocyte populations throughout the follow-up. Relapses were observed in four children during tapering of prednisone; they were not reported after discontinuation of steroid therapy.

Taken together data obtained in the presented population can lead to the following suggestions for the management of pulmonary sarcoidosis in children. BAL should be performed at the initial evaluation to document alveolitis; however, nothing seems to be gained from repeating this investigation during follow-up in the absence of specific reasons. Once the decision to initiate glucocorticoid therapy is made, 18 months may be a reasonable treatment duration. Discontinuation of therapy can be decided even if the pulmonary function tests remain abnormal, but the child should then be carefully monitored for a relapse.

Eur Respir J 2001; 17: 628-635.

*Dept de Pneumologie PediatriqueINSERM U515 and ${ }^{\#}$ Dept de Pathologie, Hôpital Armand Trousseau, Paris, France.

Correspondence: A. Clement Dept de Pneumologie Pediatrique Hôpital Armand Trousseau

26, Ave Dr Netter

75012 Paris

France

Fax: 330144736725

Keywords: Bronchoalveolar lavage children

corticosteroids

pulmonary function tests

pulmonary sarcoidosis

Received: March 222000

Accepted after revision July 102000
Sarcoidosis is a chronic inflammatory disease in which granulomatous lesions can develop in many organs, predominantly the lung [1-3]. Its cause remains obscure but probably involves environmental and host factors. Therefore, the diagnosis of sarcoidosis is currently based on a combination of suggestive clinical features with histologically-documented noncaseating granulomas, in the absence of other known causes of granuloma formation.

Sarcoidosis occurs chiefly in adults, with marked racial differences, and with estimated prevalences ranging $<1-40$ cases per 100,000 population [2]. Although the incidence of sarcoidosis in children is difficult to assess, it is generally believed to be lower than in adults. Milman et al. [4] recently reported that the approximate calculated incidence of sarcoidosis in children in Denmark was 0.27 per 100,000 children per yr [4]. Paediatric sarcoidosis is usually diagnosed in patients $>10 \mathrm{yr}$, with a peak in 13-15-yr group.
The decision to treat pulmonary sarcoidosis in adults remains difficult, as there is no consensus on which patients should receive treatment $[2,5,6]$. This is because the disease can stabilize or resolve without therapy. In particular, it is well recognized that acute pulmonary sarcoidosis remits spontaneously in nearly two-thirds of cases. Spontaneous remissions usually occur within the first few months after the diagnosis, but are occasionally seen after a longer period. The decision to treat adults with sarcoidosis must therefore be based on a set of factors including disease presentation, disease progression, and severity of pulmonary dysfunction [2, 7-9].

Deciding when to treat is even more difficult in paediatric patients with pulmonary sarcoidosis. In addition, in patients selected for treatment, the optimal length of treatment remains unknown since there are no studies with sufficiently large patient populations to allow a comparative evaluation of several treatment 
strategies. The few reports in the literature suggest that pulmonary sarcoidosis may run a more aggressive course in children than in adults [10-16]. As pointed out by Pattishall and Kendig [15] in their review on paediatric sarcoidosis, data on the course of sarcoidosis in children are still meagre, and additional monitoring and reporting of the long-term effects of sarcoidosis in children are warranted [15]. The aim of the present work was to gather follow-up information on pulmonary outcomes in children with sarcoidosis and to obtain data of relevance to a discussion of the optimal length and regimen of glucocorticoid therapy.

\section{Materials and methods}

\section{Study population}

The study population was recruited from the population of patients referred to the paediatric pulmonary department for sarcoidosis over a 10-yr period (1985-1995). Patient criteria for enrollment in this retrospective study including the following: 1) a biopsyproven sarcoidosis with presence of noncaseating epithelial cell granuloma and exclusion of other granulomatous lung disorders; and 2) a documented followup of at least 4 yrs.

\section{Initial evaluation}

Initial evaluation included a complete history with review of duration and severity of symptoms and physical examination, chest radiographs, pulmonary function tests and bronchoalveolar lavage (BAL). Lung involvement was documented on the presence of abnormalities of either pulmonary function tests, chest radiographs, or BAL data.

Chest radiographs were analyzed independently by two readers and classified in a standard manner according to the traditional roentgenographic stages $[2$, 5]. The pulmonary function tests included measurements of the vital capacity (VC), dynamic lung compliance $(C \mathrm{~L}, \mathrm{dyn})$, lung transfer for $\mathrm{CO}(T \mathrm{~L}, \mathrm{CO})$, and arterial blood gases. Results of pulmonary function tests were expressed as a percentage of the predicted values ( $\%$ pred) for height-matched children: $C \mathrm{~L}$,dyn and $T \mathrm{~L}, \mathrm{CO}$ values $<75 \%$ and $\mathrm{VC}$ values $<80 \%$ pred were considered as significantly decreased [17].

BAL was performed during bronchoscopy under local anaesthesia, as previously described [16, 18]. Briefly, patients were premedicated with atropine and midazolam, and local anaesthesia was achieved with topical lidocaine. The bronchoscope was wedged into a subsegmental bronchus of the lower right lobe. The volume of sterile normal saline instilled was equivalent to $3 \mathrm{~mL} \cdot \mathrm{kg}$ body weight ${ }^{-1}$. The sterile solution at $37^{\circ} \mathrm{C}$ was injected in six aliquots and withdrawn by gentle aspiration. The first aliquot was used for microbiological studies. The remaining recovered fluid was pooled and filtered through sterile gauze, and samples were removed for total and differential cell counts. Lymphocyte subpopulation studies (CD4+, CD8+) were determined using a standard double immunofluorescence assay, as previously described [16, 18].
Other investigations included blood laboratory tests with angiotensin-converting enzyme determination, eye examination by an ophthalmologist, and cardiac evaluation.

\section{Corticosteroid therapy and follow-up}

The follow-up was performed by the physician in the department who entered the patient in the study. The criteria used for instituting steroid therapy were clinical (patients with respiratory symptoms interfering with daily activities, and/or patients with systemic symptomatic disease), and/or functional $\mathrm{VC}$ and/or $T \mathrm{~L}, \mathrm{CO}$ $<60 \%$ pred.

The protocol of corticosteroid therapy used was the following. Oral prednisone was started at $1 \mathrm{mg} \cdot \mathrm{kg}^{-1}$. day $^{-1}$ for 6-8 weeks. A gradual reduction in the dosage was then initiated, guided by the disease progression to a level of $15 \mathrm{mg}$.day for at least 6 months. After this first period, the physician was at liberty to choose between a daily treatment or to institute an alternate day dosings. The steroid treatment was then decreased slowly over several months to the equivalent of $5 \mathrm{mg}$ prednisone daily [16]. In case of relapse, steroid treatment was increased up to $1 \mathrm{mg} \cdot \mathrm{kg}^{-1} \cdot \mathrm{day}^{-1}$ for the required amount of time necessary to control the disease, and then tapered again. During the follow-up, all patients were evaluated at several time points, and complete pulmonary investigations were repeated including chest radiographs, pulmonary function tests and BAL. Tolerance of glucocorticoid treatment was monitored with evaluation of effects on growth, hypothalamic-pituitary-adrenal axis, and bone and glucose metabolism [19].

\section{Statistical analyses}

Data are presented as mean \pm SEM. All analysis were performed with the use of a commercial software pakage (Statistica for windows, release 5.1; Stat Soft France, Maison Alfort, France). Statistical comparison of values obtained at the various time points was evaluated by analysis of variance for repeated measures (Friedman ANOVA test) followed by the Wilcoxon test. A p-value $<0.05$ was considered significant.

\section{Results}

\section{Presentation of the patients}

From the population of children referred to the department during the 10 -yr period, 21 patients fulfilled the two criteria of enrollment in the study: a documented sarcoidosis and a follow-up of at least 4 yrs. Seven children were diagnosed before the age of 10 yrs. There was no difference in terms of sex. Twelve patients were Black. Characteristics of the patients are given in table 1. They were all symptomatic. The main symptom was fever observed in seven cases. Nonspecific symptoms also included weight loss in three cases and fatigue. Other presentations were 
Table 1. - Characteristics of patients with sarcoidosis at initial evaluation

\begin{tabular}{|c|c|c|c|c|}
\hline $\begin{array}{l}\text { Patient } \\
\text { No. }\end{array}$ & Sex & Race & $\begin{array}{c}\text { Age } \\
\text { yrs }\end{array}$ & Clinical manifestations \\
\hline 1 & $\mathrm{~F}$ & Black & 13 & Dyspnoea \\
\hline 2 & $\mathrm{M}$ & Caucasian & 13 & Dyspnoea \\
\hline 3 & $\mathrm{~F}$ & Caucasian & 13 & Lofgren's syndrome \\
\hline 4 & $\mathrm{~F}$ & Black & 6 & Lymphadenopathy \\
\hline 5 & $\mathrm{~F}$ & Caucasian & 16 & Lofgren's syndrome \\
\hline 6 & $\mathrm{~F}$ & Caucasian & 8 & Uveitis \\
\hline 7 & $\mathrm{M}$ & Caucasian & 2 & Arthritis, skin lesions \\
\hline 8 & $\mathrm{M}$ & Black & 5 & Fever, uveitis \\
\hline 9 & $\mathrm{~F}$ & Black & 11 & Weight loss, dyspnoea \\
\hline 10 & $\mathrm{~F}$ & Caucasian & 12 & Lymphadenopathy, parotidis \\
\hline 11 & $\mathrm{M}$ & Black & 7 & Fever, fatigue \\
\hline 12 & M & Caucasian & 13 & Fever, weight loss \\
\hline 13 & $\mathrm{M}$ & Black & 12 & Fever, weight loss, dyspnoea \\
\hline 14 & $\mathrm{~F}$ & Black & 11 & Lymphadenopathy \\
\hline 15 & $\mathrm{~F}$ & Black & 11 & Fever, dyspnoea \\
\hline 16 & M & Caucasian & 12 & Fever, dyspnoea \\
\hline 17 & $\mathrm{~F}$ & Black & 12 & Uveitis \\
\hline 18 & $\mathrm{~F}$ & Caucasian & 14 & Uveitis \\
\hline 19 & $\mathrm{M}$ & Black & 9 & Parotidis \\
\hline 20 & $\mathrm{~F}$ & Black & 15 & Fever, fatigue \\
\hline 21 & M & Black & 6 & Uveitis \\
\hline
\end{tabular}

F: female; M: male.

related to specific organ system involvement with dyspnoea (six cases), uveitis (five cases), peripheral lymphadenopathy (three cases), skin lesions (three cases), parotid gland enlargement (two cases), and arthritis (one case).

\section{Organ involvement}

Complete investigation of the patients when referred to the department led to documented lung involvement in all of them (tables 2 and 3). As indicated above, only six displayed respiratory symptoms. Abnormal chest radiograph was found in 11 children. Bilateral hilar lymphadenopathy (stage I) was observed in three cases, bilateral hilar lymphadenopathy with pulmonary infiltrates (stage II) in four cases, and parenchymal infiltrates without hilar adenopathy (stage III) in four cases. Pulmonary function tests at initial evaluation were found normal in only three patients (table 3 ). In the other patients, abnormal pulmonary function was documented. Alteration of TL,CO was found in 12 patients, whereas decrease in $C \mathrm{~L}$,dyn was observed in 14 children. Reduction in VC was found in nine cases and was always associated with alterations of either $C \mathrm{~L}$,dyn, $T \mathrm{~L}, \mathrm{CO}$, or both. Hypoxaemia was noticed in three patients (patients $8,11,12$ ).

Results of BAL at initial evaluation are listed in table 3 . They were compared to the results previously reported in a control paediatric population, which indicated: total number of cells (mean \pm SEM): $350.6 \pm$ $45.9 \times 10^{3}$ cells $\cdot \mathrm{mL}^{-1}$; relative proportion of macrophages: $89.9 \pm 1.3 \%$; relative proportion of lymphocytes: $8.9 \pm 1.4 \%$; relative proportion of neutrophils: $1.2 \pm 0.3 \%$, and $\mathrm{CD} 4+/ \mathrm{CD} 8+$ ratio $(0.8 \pm 0.1)$ [18]. Results of BAL in the present study indicated a mean total number of cells of $461.9( \pm 57.1) \times 10^{3}$ cells $\cdot \mathrm{mL}^{-1}$. In all children the relative proportion of lymphocytes was increased with a mean value of $42.7 \%( \pm 3.2 \%)$. This increase was associated with an increased CD4+/CD8+ ratio $(3.9 \pm 0.6)$. The relative proportion of neutrophils was also enhanced $(4.5 \pm 1.6 \%)$.

In addition to lung, organ involvement included mainly the liver, the eyes and the skin. In nine children an anterior uveitis was documented, whereas skin lesions were found in seven cases with mainly erythema nodosum and maculopapular eruptions. Presence of peripheral lymphadenopathy was noticed in five children. Cardiac abnormalities were found in three cases,

Table 2. - Diagnosis of sarcoidosis and organ involvement

\begin{tabular}{|c|c|c|c|c|}
\hline $\begin{array}{l}\text { Patient } \\
\text { No. }\end{array}$ & Biopsy & Organ involvement & $\begin{array}{c}\text { Chest radiograph } \\
\text { stages }\end{array}$ & $\underset{U \cdot L^{-1}}{\text { Serum } A C E}$ \\
\hline 1 & Tonsil & Lung, tonsils & 0 & 114 \\
\hline 2 & Adenoids & Lung, adenoids & 0 & 255 \\
\hline 3 & Liver & Lung & I & 161 \\
\hline 4 & Lympadenopathy & Lung, lymphoid system & 0 & 226 \\
\hline 5 & Liver & Lung, skin & I & ND \\
\hline 6 & Liver & Lung, eyes & 0 & 125 \\
\hline 7 & Skin & Lung, eyes, skin, joints & III & 88 \\
\hline 8 & Liver, kidney & Lung, Kidney, eyes & I & 118 \\
\hline 9 & Lung, liver & Lung, eyes, joints, parotid & III & 136 \\
\hline 10 & Lymphadenopathy & Lung, parotid, lymphoid \& nervous systems & II & 32 \\
\hline 11 & Stomach & Lung, liver, pancreas stomach, lymphoid system & 0 & 412 \\
\hline 12 & Lung & Lung, heart & II & 97 \\
\hline 13 & Liver & Lung, liver & II & 266 \\
\hline 14 & Lymphadenopathy & Lung, joints, lymphoid system & 0 & 70 \\
\hline 15 & Lung, liver & Lung, heart, eyes & III & 325 \\
\hline 16 & Lung, liver & Lung & III & 220 \\
\hline 17 & Liver & Lung, eyes & 0 & 118 \\
\hline 18 & Kidney & Lung, eyes, kidney & 0 & 87 \\
\hline 19 & Skin & Lung, skin, testis, lymphoid system & 0 & 127 \\
\hline 20 & Lymphadenopathy & Lung, eyes, heart, lymphoid system & II & ND \\
\hline 21 & Liver & Lung, eyes & 0 & 146 \\
\hline
\end{tabular}

ACE: angiotensin converting ensyme; ND: not determined. 
Table 3. - Pulmonary function tests and bronchoalveolar (BAL) studies at initial evaluation

\begin{tabular}{|c|c|c|c|c|c|c|c|c|}
\hline \multirow{2}{*}{ Patient No } & \multicolumn{3}{|c|}{ Pulmonary function tests } & \multicolumn{5}{|c|}{ BAL studies } \\
\hline & $\mathrm{VC} \%$ & $T \mathrm{~L}, \mathrm{CO} \%$ & $C \mathrm{~L}$, dyn $\%$ & Total cells $\cdot \mathrm{mL}^{-1} \times 10^{3}$ & AM $\%$ & $\mathrm{~L} \%$ & $\mathrm{~N} \%$ & $\mathrm{CD} 4+/ \mathrm{CD} 8+$ \\
\hline 1 & 87 & 123 & 75 & 80 & 47 & 53 & 0 & 1 \\
\hline 2 & 102 & 107 & 103 & 1020 & 66 & 31 & 3 & ND \\
\hline 3 & 96 & 66 & 111 & 330 & 52 & 47 & 1 & 5.8 \\
\hline 4 & 80 & 87 & 95 & 620 & 65 & 31 & 4 & ND \\
\hline 5 & 94 & 56 & ND & 180 & 39 & 38 & 23 & 5.4 \\
\hline 6 & 60 & 52 & 49 & 820 & 45 & 52 & 2 & 3.7 \\
\hline 7 & 63 & 39 & 42 & 430 & 39 & 60 & 1 & 3.7 \\
\hline 8 & 48 & 57 & 22 & 160 & 67 & 26 & 7 & ND \\
\hline 9 & 93 & 85 & 56 & 500 & 62 & 37 & 1 & 1.3 \\
\hline 10 & 75 & 65 & 56 & 930 & 57 & 43 & 0 & 4 \\
\hline 11 & ND & 54 & 85 & 750 & 26 & 72 & 2 & 1.7 \\
\hline 12 & ND & 83 & 55 & 280 & 34 & 61 & 5 & 5.7 \\
\hline 13 & ND & 26 & 14 & 200 & 61 & 39 & 0 & 2.3 \\
\hline 14 & 60 & 65 & 41 & 610 & 58 & 16 & 23 & 2 \\
\hline 15 & 48 & 46 & 35 & 400 & 58 & 40 & 2 & 13 \\
\hline 16 & 59 & 96 & 49 & ND & 64 & 19 & 17 & 7 \\
\hline 17 & 82 & 102 & 61 & 240 & 55 & 42 & 1 & ND \\
\hline 18 & 96 & 60 & 91 & 470 & 31 & 68 & 1 & 3.5 \\
\hline 19 & 56 & 90 & 60 & 300 & 54 & 42 & 4 & 1.6 \\
\hline 20 & 63 & 52 & 72 & 350 & 55 & 44 & 1 & 2.3 \\
\hline 21 & 51 & 80 & 65 & 670 & 63 & 36 & 1 & 2.1 \\
\hline
\end{tabular}

VC: vital capacity; TL,CO: lung transfer for $\mathrm{CO}$; $C \mathrm{~L}$,dyn: dynamic lung compliance; AM: alveolar macrophages; L: lymphocytes; $\mathrm{N}$ : neutrophils; CD4+/CD8+: $\mathrm{CD}+$ lymphocyte and $\mathrm{CD} 8+$ lymphocyte subpopulations ratio; ND: not determined.

with the presence of segmental defects on thallium-201 scans. Other organs involved included joints (two cases), kidney (two cases of renal dysfunction related to local infiltration of sarcoid granulomas), parotid glands (two cases), and, in one case each, stomach, tonsil, testis, and adenoids [20-24]. Results of serum angiotensin converting enzyme are listed in table 2 . Elevated values were observed in 13 children (range of normal values: $\left.35-115 \mathrm{U} \cdot \mathrm{L}^{-1}\right)$.

\section{Diagnosis}

As indicated above, the diagnosis of sarcoidosis was based on histological confirmation of granuloma. The sites of tissue biopsy are listed in table 2 . The organs mainly biopsied were the following: liver tissues in 10 cases, lung biopsies in four cases, and enlarged peripheral lymph nodes in four children. It should be noted that three patient biopsy specimens were obtained from two different sites.

\section{Follow-up evaluation}

Patient management. During the follow-up, all patients were evaluated at several time points, and complete pulmonary investigations with pulmonary function tests and BAL were repeated. As indicated above, the decision to treat the patients with corticosteroids was based on a number of factors including clinical symptoms, alterations of pulmonary function tests, degree of involvement of the various organs, and disease progression [2, 8]. In four children, there was no indication for treatment at initial evaluation, as well as during the follow-up (patients 1-4). Seventeen children were treated with corticosteroids according to the strategy indicated above (patients 5 to 21). In this group, patient surveillance indicated a rapid improvement of symptoms within the first months of treatment. Disappearance of chest radiograph abnormalities was noticed in 10 cases at the evaluation performed after 6 months of follow-up. As indicated in table 4, relapses were observed in four patients. These relapses were defined as a return of respiratory manifestations. They occurred during tapering of prednisone respectively after 9 and 12 months of steroid treatment institution, and they were rapidly controlled by increasing the dosages of corticosteroids.

Table 4. - Patient follow-up

\begin{tabular}{lccc}
\hline $\begin{array}{l}\text { Patient } \\
\text { No. }\end{array}$ & Relapses & $\begin{array}{c}\text { Treatment duration } \\
\text { yrs }\end{array}$ & $\begin{array}{c}\text { Follow-up } \\
\text { duration yrs }\end{array}$ \\
\hline 5 & No & 3 & 7 \\
6 & No & 4 & 9 \\
7 & Yes 9 & 3 & 4 \\
8 & No & 5 & 9 \\
9 & No & 4 & 6 \\
10 & No & 1.5 & 4 \\
11 & No & 1.5 & 4 \\
12 & No & 3 & 4 \\
13 & No & 2 & 5 \\
14 & No & 4 & 5 \\
15 & Yes 12 & 4 & 6 \\
16 & Yes & 4 & 4 \\
17 & No & 3 & 4 \\
18 & No & 2 & 7 \\
19 & Yes 12 & 3 & 4 \\
20 & No & 3 & 6 \\
21 & No & 3 & \\
\hline
\end{tabular}

Relapses: number of months after initiation of treatment. 
Several side effects of steroid treatment were observed during the periods with high dose prednisone, mainly weight gain and cushingoid features. For each patient, the duration of treatment as well as the duration of follow-up are reported in table 4 . No relapses were reported after discontinuation of steroid therapy. Nine children were followed-up for more than 4 yrs. Reappearance of pulmonary symptoms was not reported in any of them, and results of pulmonary function tests remained similar to the results documented at the last evaluation included in the present study.

Pulmonary function test results. Pulmonary function tests were repeated several times during the follow-up. In the group of nontreated children, pulmonary function tests performed after 6 months of follow-up were normal (data not shown). They remained in the normal range of values throughout the study.

In the group of treated patients, results of pulmonary function tests obtained at the following time points: 6 months, 12 months, 18 months, and $3-4 \mathrm{yr}$, are reported in figures 1-3. Data obtained after 6 months of treatment showed a significant improvement of VC (mean $\pm \mathrm{SEM}$ ): $76.0 \pm 5.9 \%$ (compared to $67.7 \pm 4.6 \%$ at initial evaluation; $\mathrm{p}=0.046$ ). For $T \mathrm{~L}, \mathrm{CO}$, the mean value was increased and fell within the normal range: $78.4 \pm 5.3 \%$ (compared to $65.1 \pm 5.4 \%$ at initial evaluation). By contrast, the mean $C \mathrm{~L}$,dyn value was not significantly increased and remained below the normal range: $66.7 \pm 5.2 \%$ (compared to $53.3 \pm 5.1 \%$ at initial evaluation). At the evaluation performed after 12 months of treatment, the results of $\mathrm{VC}$ and $T \mathrm{~L}, \mathrm{CO}$ were similar to the results obtained after 6 months of treatment. Also, no significant changes of $C \mathrm{~L}$,dyn could be documented, with the persistence of decreased values: $64.0 \pm 4.6 \%$. After 18 months of treatment, the results of $\mathrm{VC}, C \mathrm{~L}$,dyn and $T \mathrm{~L}, \mathrm{CO}$ were similar to the results obtained at the evaluation at 12 months, with the following results: VC: $77.2 \pm 4.6 \%$; CL,dyn: $65.9 \pm$ $4.9 \%$; TL,CO: $92.4 \pm 6.3 \%$. After $3-4 \mathrm{yr}$ of follow-up, no

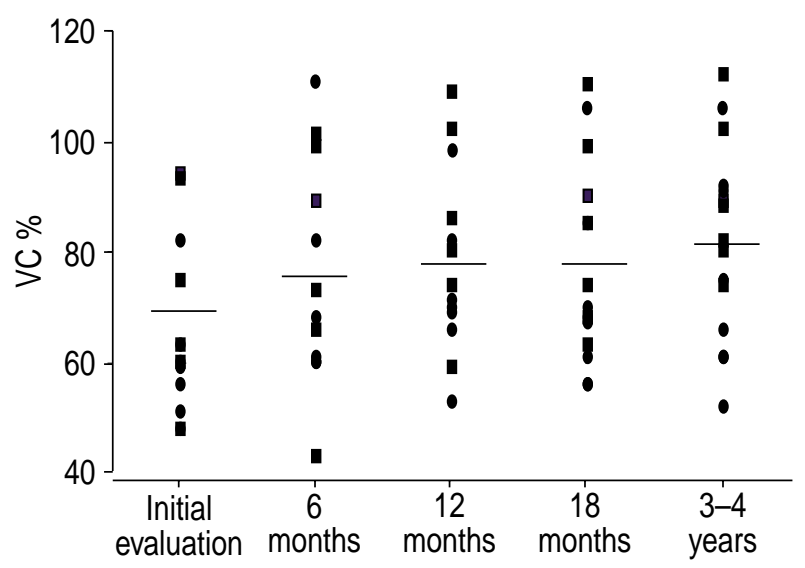

Fig. 1. - Vital capacity (VC) data in the group of patients who received corticosteroid treatment. Vital capacity results were obtained at initial evaluation and during the follow-up at respectively 6 months, 12 months, 18 months, and 3-4 yrs. VC values $<80 \%$ of the predicted values were considered as significantly decreased. Individual values and mean are shown on the graphs. - patients on daily dosing regimen; 0 : patients on alternateday dosing regimen.

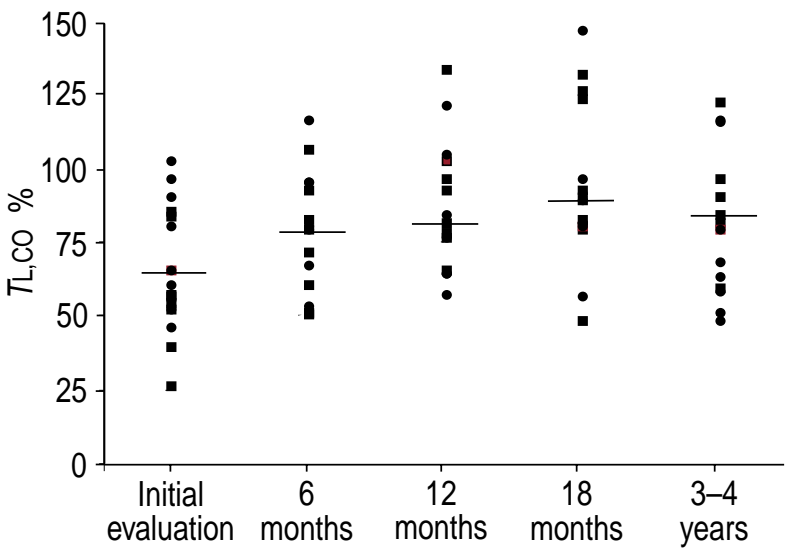

Fig. 2. - Lung transfer for carbon monoxide $(T \mathrm{~L}, \mathrm{CO})$ data in the group of patients who received corticosteroid treatment. TL,CO results were obtained at initial evaluation and during the followup at respectively 6 months, 12 months, 18 months, and 3-4 yrs. $T \mathrm{~L}, \mathrm{CO}$ values $<75 \%$ of the predicted values were considered as significantly decreased. Individual values and mean are shown on the graphs. $\mathbf{\square}$ : patients on daily dosing regimen; 0 : patients on alternate-day dosing regimen.

changes in pulmonary function tests could be observed, with the following results: VC: $82.1 \pm 4.5 \%$; $C \mathrm{~L}, \mathrm{dyn}$ : $61.5 \% \pm 5.5 \%$; TL,CO: $80.6 \pm 6.1 \%$.

After 6 months of daily prednisone, an alternate dosing treatment was introduced in eight children (patients 14-21). To determine whether treatment regimen could have influenced disease progression, results of pulmonary function tests were compared in the following subgroups of treated children: subgroup A (patients 5-13) with daily treatment and subgroup B (patients 14-21) with alternate dosing treatment. In subgroup A, no significant changes of the values of either VC, CL,dyn or TL,CO could be observed throughout the studied period. In subgroup $B$, results of $C \mathrm{~L}$,dyn were lower at the evaluation performed after

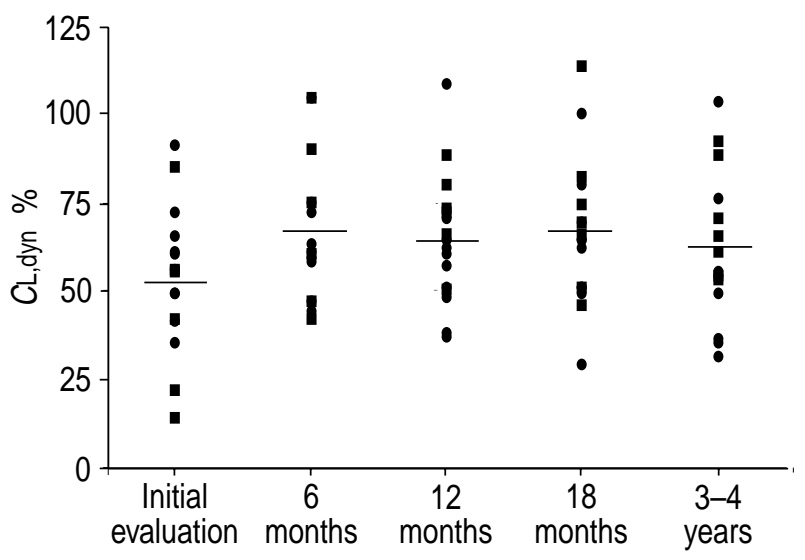

Fig. 3. - Dynamic lung compliance $(C \mathrm{~L}, \mathrm{dyn})$ data in the group of patients who received corticosteroid treatment. Results were obtained at initial evaluation and during the follow-up at respectively 6 months, 12 months, 18 months, and 3-4 yrs. CL,dyn values $<75 \%$ of the predicted values were considered as significantly decreased. Individual values and mean are shown on the graphs. $\mathbf{\square}$ : patients on daily dosing regimen; 0 : patients on alternate-day dosing regimen. 
3-4 yr of follow-up $(54.9 \pm 8.6 \%)$ compared to the values documented after 6 months of treatment $(67.9 \pm 6.7 \%)$; however this difference did not reach statistical significance. As indicated in table 4, nine children were followed-up for $>4$ yrs. Results of their pulmonary function tests after 4 yrs remained similar to the results documented at the last evaluation reported in figures 1-3 (data not shown).

\section{Bronchoalveolar results}

In the group of nontreated children, results of BAL studies at the end of the first year of follow-up indicated
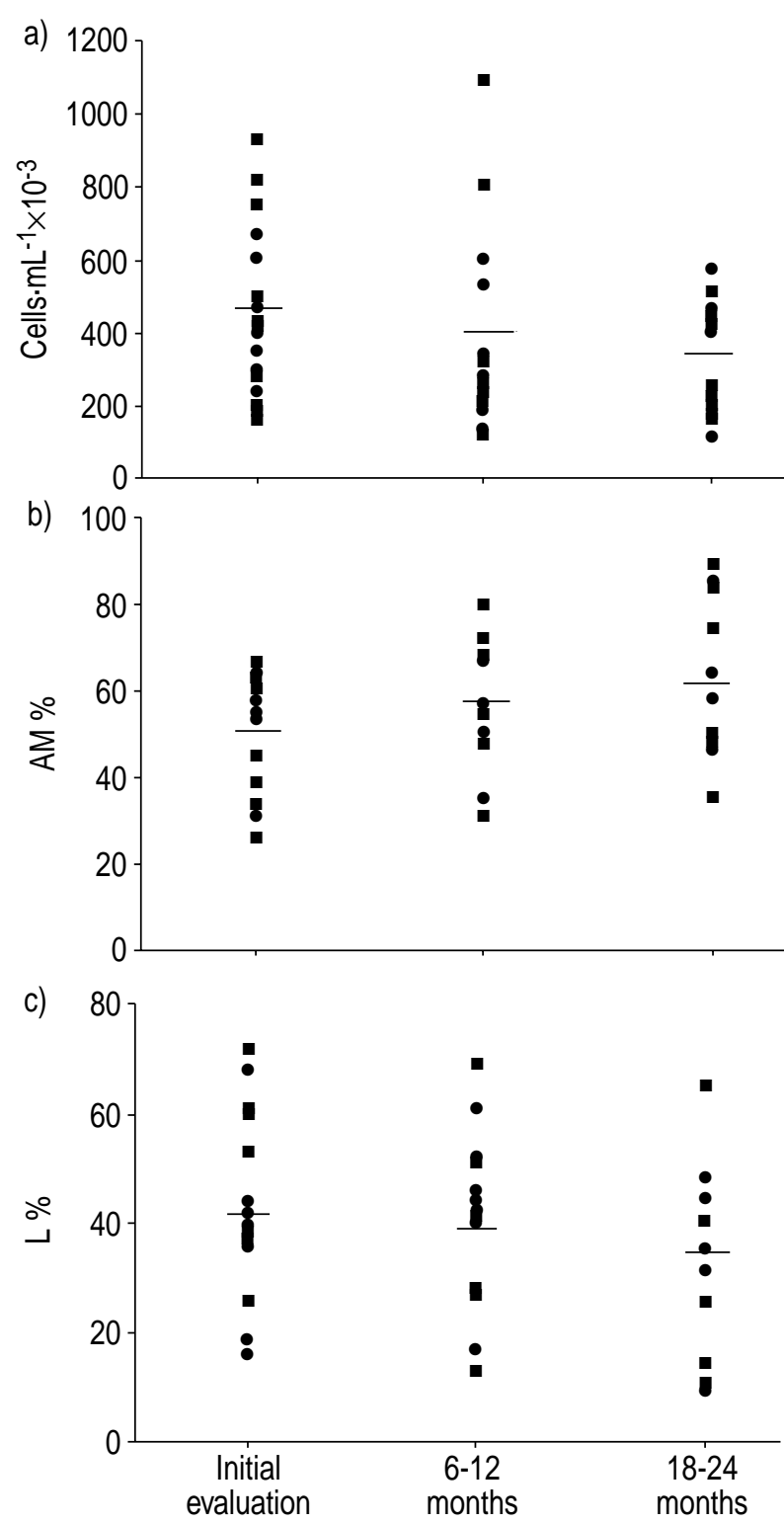

Fig. 4. - Bronchoalveolar lavage data in the group of patients who received corticosteroid treatment. a) Total cells $\mathrm{mL}^{-1} \times 10^{3}$, b) percentages of alveolar macrophages (AM), and c) percentages of lymphocytes (L) were obtained at initial evaluation and during the follow-up at respectively 6-12 months, and 18-24 months. Individual values and mean are shown on the graphs. $\mathbf{\square}$ : patients on daily dosing regimen; 0 : patients on alternateday dosing regimen. persistence of increased percentages of lymphocytes: $32 \pm 7.5 \%$. In the group of treated patients, results of BAL studies performed at the end of the first and second year of treatment showed that the relative proportion of lymphocytes remained significantly increased with respectively (mean \pm SEM): $39.3 \pm 4.3 \%$, and. $33.6 \pm 5.4 \%$ (fig. 4 ). The relative proportion of neutrophils also remained enhanced, $3.4 \pm 1.3 \%$, and $3.2 \pm 0.9 \%$ respectively. No differences could be observed between subgroups $\mathrm{A}$ and $\mathrm{B}$.

\section{Discussion}

In the present work, the course of pulmonary disease was analysed in a group of children with sarcoidosis. Data relevant to a discussion of glucocorticoid therapy strategies in paediatric sarcoidosis was obtained was obtained. This is important since at present there is an urgent need for defining the optimal length and regimen of glucocorticoid therapy in children.

The study children were followed at a single centre and consequently were not representative of the overall paediatric population with a diagnosis of sarcoidosis. The characteristics of the patients call for a number of comments. Firstly, seven children were $<10$ yrs of age at diagnosis. Although paediatric sarcoidosis is most common at 13-15 yrs of age, its age-specific incidence and prevalence remain uncertain, since it is, without doubt, an underdiagnosed condition [15]. There are several reasons for this, the disease can be asymptomatic, particularly in its earliest stages; and in most countries children do not have routine annual chest radiographs. In the present work, a group of ophthalmologists referred all cases of paediatric uveitis of unknown origin to the authors department, a fact that explains the large proportion of patients with uveitis as the presenting symptom $[20,25]$. It is worth pointing out that among the seven children $<10 \mathrm{yrs}$ of age at diagnosis, three were investigated because of uveitis. Secondly, the data support previously reported differences in the racial distribution of sarcoidosis [2, 6]. Marked racial differences in the incidence and prevalence of sarcoidosis have been reported by many authors. As an example, in the USA the prevalence of adult sarcoidosis is approximately three times higher in Blacks than in Caucasians. Various reports in the literature also indicate that race and ethnicity affect both the patterns of organ involvement and disease severity. The present findings are in keeping with these data: 12 children were Black; among the seven children $<10$ yrs of age at diagnosis, five were black; and the number of organs involved was higher in the Black than in the Caucasian children.

At present, the management of sarcoidosis remains empirical as there is no consensus on which patients should be treated. This is because the course of the disease is difficult to predict in an individual patient. In addition, there is ample evidence that many adults experience spontaneous remission within six months of the diagnosis [26-28]. The degree of uncertainty surrounding the treatment of sarcoidosis is even greater in children than in adults since few paediatric studies have been published and long-term data from adults 
may not be relevant to children. In children, events related to lung growth may influence the course of the sarcoidosis [16]. In a recent study, MARCILLE et al. [29] analysed data from 19 patients diagnosed with sarcoidosis in childhood and followed for a mean of 21 yrs. Pulmonary function tests remained abnormal in $68 \%$ of the patients. Although the adults included in this study may not be representative of the population of patients with a diagnosis of sarcoidosis during childhood, the findings suggest that the long-term outcome of sarcoidosis may be different in children and adults.

In the present study, four patients were initially managed by watchful waiting. All four had mild symptoms, and three had normal pulmonary function test results; the exception (patient 3) had Löfgren's syndrome, which is known to be associated with a good prognosis. During follow-up, repeated pulmonary function testing showed normal results. The initial BAL fluid contained an increased population of lymphocytes. In the two children who underwent repeated BAL 1 and 2 yrs after the diagnosis, the results showed persistently high percentages of lymphocytes, with an increased CD4+/CD8+ ratio.

Glucocorticoid treatment was initiated in 17 children. This proportion is high compared to studies in adults. The decision to give glucocorticoid therapy was based on the clinical presentation and symptoms, the sites and types of extrapulmonary disease, and the results of pulmonary function tests. At initial evaluation, all 17 children had alterations in $\mathrm{VC}$, and/or $C \mathrm{~L}$,dyn, and/or $T \mathrm{~L}, \mathrm{CO}$, and 11 had chest radiograph abnormalities. Oral prednisone was started at a dosage of $1 \mathrm{mg} \cdot \mathrm{kg}^{-1} \cdot \mathrm{day}^{-1}$, and the treatment regimen was subsequently adjusted based on disease progression. During the first 6 months, prednisone was given daily. All 17 children underwent repeated physical evaluations, during which the presence, nature, and severity of symptoms were noted. After 6 months, the chest radiograph had returned to normal in 10 of the 11 children with initial abnormalities. Improvements were seen in the VC and TL,CO. By contrast, no significant modifications in BAL results were recorded. After 12 and 18 months, pulmonary function test results were unchanged as compared to the 6 month evaluation, and all 17 children had normal chest radiographs. No further significant improvements were seen in pulmonary function tests performed during the 3-4 yr of follow-up. Interestingly, BAL studies showed a persistent increase in the proportion of lymphocytes throughout follow-up. These data confirm an earlier study in which it was found that the proportion of $\mathrm{T}$-cells and the $\mathrm{CD} 4+/ \mathrm{CD} 8+$ ratio remained abnormally high after 2 yrs of glucocorticoid therapy in eight children with sarcoidosis [16]. It should be pointed out that the patients included in the present study received no drugs other than glucocorticoids.

The glucocorticoid treatment strategy during the first 6 months was similar in all 17 children. After 6 months, the physician in charge of the patient could either continue daily dosing or switch to alternate-day dosing. Nine patients were continued on daily dosing and eight were switched to alternate-day dosing. Three relapses occurred in the alternate-day group versus one in the daily group. Also, $C$ L,dyn values were lower after 3-4 yrs in the alternate-day group. These results suggest that alternate-day dosing may be less beneficial than daily dosing. As in adult sarcoidosis, an issue of crucial importance is the optimal length of glucocorticoid treatment in paediatric sarcoidosis. Several studies have documented the short-term efficacy of glucocorticoids in adults. However, a recent statement on sarcoidosis recommends that glucocorticoid treatment should be continued for at least 12 months $[2,30]$. PAtTishall and coworkers $[14,15,31]$ concluded in their reviews on sarcoidosis in children that longer treatment may be required. In the patients of the present study, prolonged treatment was used empirically, the mean duration being 3 yrs. Resolution of most clinical manifestations and improvements in pulmonary function tests were noted during the first 6-12 months of glucocorticoid therapy. After 18 months, however, there were no further improvements in pulmonary function tests, and BAL cytology findings remained abnormal. These results are in keeping with the follow-up data obtained by MARCILLE et al. [29] in adults with a diagnosis of sarcoidosis during childhood. In the present study population, no relapses were observed after treatment discontinuation. In twp patients (table 4), treatment was stopped after 18 months, and pulmonary investigations remained unchanged during the 2.5 yrs of posttreatment follow-up. In the 15 remaining patients, treatment duration ranged $2-5 \mathrm{yrs}$, and the mean posttreatment follow-up was 2.3 yrs; no pulmonary changes were demonstrated by physical examination or lung function testing. As indicated above, the treatment regimen in each patient was defined by the physician in charge of the patient. In the present retrospective work, it seems that the decision to give prolonged treatment was largely based on the persistence of lung function test abnormalities. However, analysis of the data suggest that this strategy may not be valid. Prolonging therapy does not seem to have modified the course of the disease, since pulmonary function test alterations persisted unchanged long after treatment discontinuation.

The present study provides information on progression of the pulmonary disease. The most striking finding is the persistence of pulmonary function test alterations and of alveolitis manifesting as an increase in bronchoalveolar fluid lymphocytes. Glucocorticoid therapy provided some improvement in the pulmonary function test abnormalities but failed to affect the bronchoalveolar fluid cytology results. Taken in aggregate, these results suggest that the following proposals of management may be appropriate. Bronchoalveolar fluid should be performed at the initial evaluation to document alveolitis; however, nothing seems to be gained from repeating this investigation during followup in the absence of specific reasons. Once the decision to initiate glucocorticoid therapy is made, treatment efficacy should be evaluated based on the clinical manifestations, chest radiographs, and pulmonary function tests. The treatment can be stopped even if the pulmonary function tests remain abnormal, but the child should then be carefully monitored for a relapse. The optimal length of therapy remains an important issue. Several biological markers of disease activity are under study but cannot yet be used to guide treatment 
decisions $[2,3,30]$. Based on the recent report of the sarcoidosis statement committee and on the follow-up data from the present study, 18 months may be a reasonable treatment duration $[2,30]$. Further followup studies are ongoing in the authors' department to gather additional information on pulmonary outcomes in paediatric sarcoidosis.

\section{References}

1. James DG. Sarcoidosis and other granulomatous disorders. New York: Marcel Dekker 1994.

2. Hunninghake GW, Costabel U, Ando M, et al. Statement on sarcoidosis. Am J Respir Crit Care Med 1999; 160: 736-755.

3. Muller-Quernheim J. Sarcoidosis: immunopathogenetic concepts and their clinical application. Eur Respir J 1998; 12: 716-738.

4. Milman N, Hoffmann AL, Byg KE. Sarcoidosis in children. Epidemiology in Danes, clinical features, diagnosis, treatment and prognosis. Acta Paediatr 1998; 87: 871-878.

5. Lynch JP, Kazerooni EA, Gay SE. Pulmonary sarcoidosis. Clin Chest Med 1997; 18: 755-785.

6. Newman LS, Rose CS, Maier LA. Sarcoidosis. $N$ Engl J Med 1997; 24: 1224-1234.

7. Costabel U, Du Bois R, Eklund A, et al. Consensus conference: activity of sarcoidosis. Eur Respir J 1994; 7: 624-627.

8. Judson MA. An approach to the treatment of pulmonary sarcoidosis with corticosteroids. The six phases of treatment. Chest 1999; 115: 1158-1165.

9. Sharma OP. Pulmonary sarcoidosis and corticosteroids. Am Rev Respir Dis 1993; 147: 1598-1600.

10. Hetherington S. Sarcoidosis in young children. Am $J$ Dis Child 1982; 136: 13-15.

11. James DG, Kendig EL. Childhood sarcoidosis. Sarcoidosis 1988; 5: 57-59.

12. Kendig EL. The clinical picture of sarcoidosis in children. Pediatrics 1974; 54: 289-292.

13. Kendig EL. Sarcoidosis in children: personal observations on age distribution. Pediatr Pulmonol 1989; 6: 69-70.

14. Pattishall EN, Strope GL, Spinola SM, Denny FW. Childhood sarcoidosis. J Pediatr 1986; 108: 169-177.

15. Pattishall EN, Kendig EL. Sarcoidosis in children. Pediatric Pulmonol 1996; 22: 195-203.

16. Chadelat K, Baculard A, Grimfeld A, et al. Pulmonary sarcoidosis in children: serial evaluation of bron- choalveolar lavage cells during corticosteroid treatment. Pediatr Pulmonol 1993; 16: 41-47.

17. Gaultier C, Chaussain M, Boule $\mathrm{M}$, et al. Lung function in interstitial lung diseases in children. Bull Eur Physiopathol Respir 1980; 16: 57-66.

18. Tessier V, Chadelat K, Baculard A, Housset B, Clement A. BAL in children. A controlled study of differential cytology and cytokine expression profiles by alveolar cells in pediatric sarcoidosis. Chest 1996; 109: 1430-1438.

19. Desmarquest P, Tamalet A, Fauroux B, et al. Chronic interstitial lung disease in children: response to highdose intravenous methylprednisolone pulses. Pediatr Pulmonol 1998; 26: 332-338.

20. Kataria S, Travathan GE, Holland JE, Kataria YP. Ocular presentation of sarcoidosis in children. Clin Pediatr 1983; 22: 793-797.

21. Elgart ML. Cutaneous sarcoidosis: definitions and types of lesions. Clin Dermatol 1986; 4: 35-45.

22. Glennas A, Kvien TK, Melby K, et al. Acute sarcoid arthitis: occurence, seasonal, onset, clinical features and outcome. Br J Rheumatol 1995; 34: 45-50.

23. Nocton JJ, Stork JE, Jacobs G, Newman AJ. Sarcoidosis associated with nephrocalcinosis in young children. J Pediatr 1992; 121: 937-940.

24. Johns CJ, Paz HL, Kasper EK, Baughman K. Myocardial sarcoidosis: course and management. Sarcoidosis 1992; 9: 31-36.

25. Rizzato G, Angi M, Fraioli P, Montemurro L, Pilotto E, Tommasini A. Uveitis as a presenting feature of chronic sarcoidosis. Eur Respir J 1996; 9: 1201-1205.

26. Du Bois RM. Corticosteroids in sarcoidosis: friend or foe? Eur Respir J 1994; 7: 1203-1209.

27. Gibson GJ, Prescott RJ, Muers MF, et al. British thoracic society sarcoidosis study: effects of long term corticosteroid treatment. Thorax 1996; 51: 238-247.

28. Gottlieb JE, Israel HL, Steiner RM, Triolo J, Patrick H. Outcome in sarcoidosis. The relationship of relapse to corticosteroid therapy. Chest 1997; 111: 623631.

29. Marcille R, McCarthy M, Barton JW, Merten DF, Spock A. Long term outcome of pediatric sarcoidosis with emphasis on pulmonary status. Chest 1992; 102: 1444-1449.

30. Costabel U, Hunninghake GW. ATS/ERS/WASOG statement on sarcoidosis. Eur Respir J 1999; 14: 735 737.

31. Pattishall EN, Strope GL, Denny FW. Pulmonary function in children with sarcoidosis. Am Rev Respir Dis 1986; 133: 94-96. 